\title{
Pneumonitis induced by methotrexate. Long-term follow-up of one case and brief review of the literature.
}

\section{Author:}

Meritxell Fernandez Matilla

Nagore Fernandez-Llanio Comella

Juan Antonio Castellano Cuesta

\section{Affiliation:}

Rheumatology section

Arnau de Vilanova-Lliria Hospital, Valencia, Spain

\section{Corresponding author:}

Meritxell Fernandez Matilla

E-mail: nerhetva@gmail.com

\begin{abstract}
:
Methotrexate induced pneumonitis is a rare $(0.3-7.5 \%)(1-3)$ but serious and potentially fatal complication (4) of the treatment with this folic acid antagonist in patients with rheumatoid arthritis (RA) and other diseases. Typically, it begins as an acute or subacute episode of dry cough, dyspnea and fever, within the first year of treatment, more frequently during the first months (mean: 36-78 weeks) (5), and, regardless of the prescribed dose, smoking habits and gender of the patient. Other risk factors such as advanced age, extra-articular manifestations of rheumatoid arthritis (especially pulmonary involvement), diabetes and elevated creatinine level, have been identified (6). If suspected, methotrexate should be discontinued immediately and respiratory support treatment plus systemic steroids at medium-high doses should be initiated. In addition, it is recommended to associate a broad spectrum antibiotic treatment, covering Pneumocystis jirovecii (7), until the infectious origin is discarded (2). We present a 71year-old female who presented this rare pathology three years ago, as a consequence of being treated with methotrexate (MTX) for rheumatoid arthritis diagnosed three months earlier.
\end{abstract}




\section{CASE PRESENTATION:}

In June 2013, a non-smoker 68-yearold woman, suffering from diabetes and seronegative-RA who had been on methotrexate plus folic acid supplementation for three months, was admitted in the Intensive Care Unit of our hospital. During the previous 24 hours, she had presented dyspnea, cough, sweating, dizziness. She had low pressure and oxygen levels, and so was initially treated with a basic support therapy and empiric antibiotic, imipenem. She had no fever, but her neutrophil count was high (78\%), without eosinophilia and a normal total leukocyte count. The initial chest X-ray study showed diffuse interstitial infiltrates in the lower air-

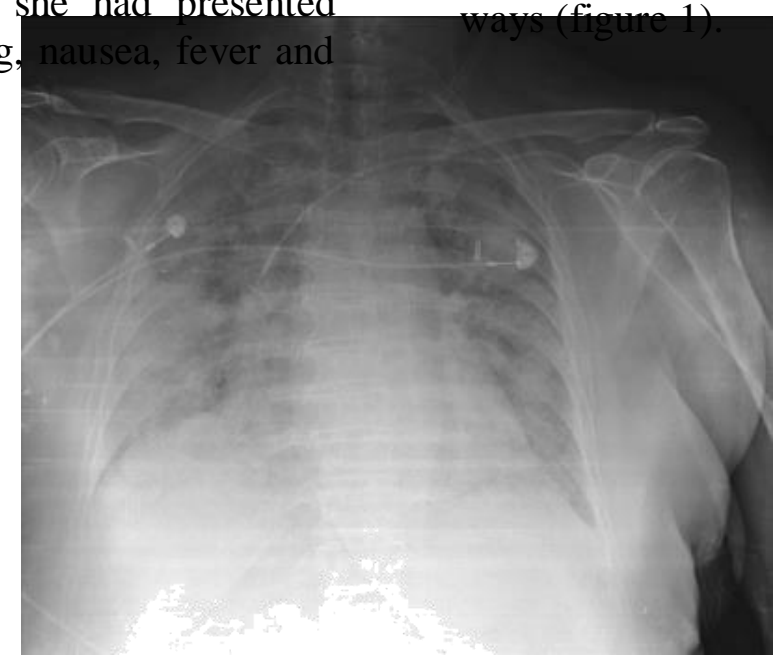

FIGURE 1. Chest X-ray on admission

Acute pulmonary edema and infection were discarded, since procalcitonin levels never raised and cultures of sputum, blood and urine were negative. Quantiferon test was negative. Taking into account her medical history, methotrexate induced pneumonitis was suspected and therefore 80 $\mathrm{mg}$ intravenous methylprednisolone was added daily to her treatment, and also methotrexate was immediately discontinued. Within two days, she improved and was moved to the hospitalization area. Pulmonary CT was performed (figure 2A), confirming the presence of an extensive bilateral ground-glass pattern of peripheral predominance, associated with minimal subpleural condensations in the lower right lobe. The preserved lung parenchyma was normal. Bronchoalveolar lavage fluid (BALF) was not done, and lung biopsy was not practiced. Echocardiographic findings showed a normal cardiac function. Pulmonary function tests were taken, but due to a lack of collaboration from the patient, results were not valid. 


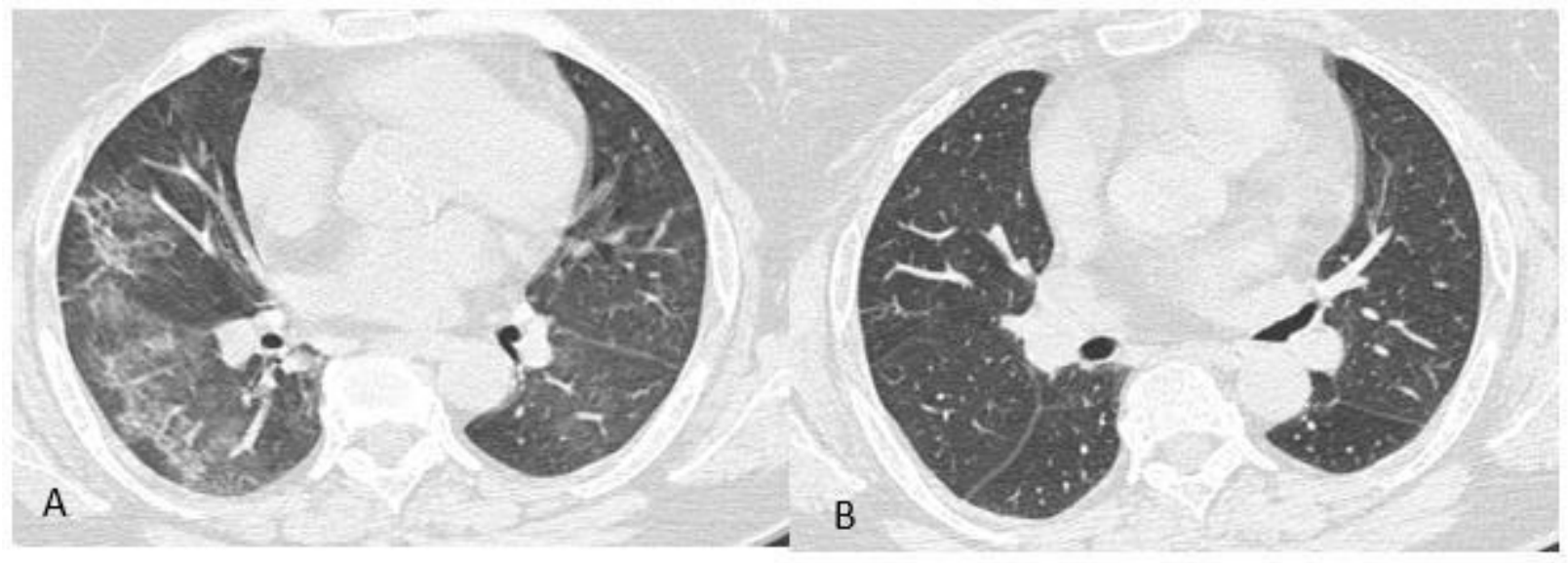

FIGURE 2. Lung CT study. A: on admission. B: after 10 months.

The patient was discharged in one week with oral steroid treatment $(0.5$ $\mathrm{mg} / \mathrm{kg} /$ day) for external follow-up. Sulphasalazine was added to her treatment, and abandoned within a few weeks due to hair loss, abdominal pain and palpable purple in her abdomen and root of her four limbs. Therefore, she continued treatment with oral prednisone alone, tapering the dose up to $7.5 \mathrm{mg} /$ day. In a few weeks, the patient was fully recovered. After 10 months, a high resolution computerized axial tomography scan was performed (figure 2B), a normal pulmonary parenchyma was observed, with disappearance of the pattern in ground glass. She completely recovered her daily activities. We tried twice to taper the steroids dose, but arthritis relapsed.

However, when arthritis had been controlled for several months with oral prednisone $(7.5 \mathrm{mg} /$ day $)$, she was referred to the Hematologist because of a chronic anemia that she had been presenting prior to the arthritis. After a bone marrow biopsy, she was diagnosed of low grade myelodysplastic syndrome, not needing further treatment, except for some iron supplements from time to time.

The patient suffered a hip fracture on October 2013, leading treatment into a more complicated issue. Her bone densitometry showed lumbar T-score -2.1 SD and total hip T-score -0.8 SD. The patient rejected Osteoporosis drug-treatment; albeit she agreed on taking a rich calcium diet and some exercise.

Currently, the patient maintains low disease activity and has a normal lifestyle. Her respiratory function remains normal. No infectious complications have been noticed. No more bone fractures have been reported.

\section{DISCUSSION:}

Immunosuppressants and immunomodulators such as methotrexate are used to adjust excessive immune response in rheumatic diseases. Unfortunately, these drugs have a potential broad toxicity spectrum, from gastric discomfort to a solid organ injury, leading into cytopenias or hair loss, among others. In 2014, Roubille and 
Pneumonitis induced by methotrexate. Long-term follow-up of one case and brief review of the literature.

Haraoui (8) performed a systematic literature review for cases related with lung toxicity in RA patients treated either with classic DMARDs, biologic DMARDs or both. This revision concluded that any of these drugs (except anakinra or hydroxychloroquine) could cause lung injury as a side effect, or even worsen a previous interstitial lung disease in a RA patient.

Regarding methotrexate therapy, induced lung toxicity has currently been described as an acute interstitial pneumonitis (hypersensitivity pulmonary reaction), interstitial fibrosis, bronchiolitis obliterans with organized pneumonia (BOOP) pleural effusion, pulmonary nodules, noncardiogenic pulmonary edema, and bronchitis with airway hyperreactivity; more rarely as a chronic pneumonitis, although this last circumstance is still under discussion. Acute interstitial pneumonitis is the most common, followed by interstitial fibrosis, with all other conditions being very rare.

All of these complications have been reported in patients with RA under low dose MTX (9), although its initial mechanism remains still unclear since published data mainly come from case reports and not from large series studies, hence no complete details from pulmonary function tests, cultures or biopsy are available, and it is important to note that real patients usually combine different pharmaceutical products which may trigger or magnify methotrexate potential by injuring the lungs. However, the most likely hypothesis explaining the methotrexate induced pneumonitis stands that an idiosyncratic hypersensitivity reaction (stimulation of type 2 alveolar cells by activated CD4 and CD8T-cell) would lead to recruitment of inflammatory cells in the lungs, leading to alveolitis (10). 
Medical Research Archives, Vol. 5, Issue 7, July 2017

Pneumonitis induced by methotrexate. Long-term follow-up of one case and brief review of the literature.

may be optimal and lung sequelae can be avoided.

\section{ACKNOWLEDGEMENTS:}

I would like to thank Dr. Bielka for her interest and patience. 
Pneumonitis induced by methotrexate. Long-term follow-up of one case and brief review of the literature.

\section{REFERENCES:}

1. Carroll GJ, Thomas R, Phatouros CC, Atchison MH, Leslie AL, Cook NJ, et al. Incidence, prevalence and possible risk factors for pneumonitis in patients with rheumatoid arthritis receiving methotrexate. J Rheumatol. enero de 1994;21(1):51-4.

2. Golden MR, Katz RS, Balk RA, Golden HE. The relationship of preexisting lung disease to the development of methotrexate pneumonitis in patients with rheumatoid arthritis. J Rheumatol. junio de 1995;22(6):1043-7.

3. Methotrexate-induced lung injury - UpToDate [Internet]. [citado 21 de mayo de 2017]. Disponible en: http://uptodates.sangva.csinet.es/content s/methotrexate-induced-lung-

injury?source $=$ search_result \&search $=\mathrm{M}$ ethotrexateinduced $\% 20$ lung\%20injury\&selectedTit $\mathrm{le}=1 \sim 150$

\section{Mateo-Soria L. Toxicidad} pulmonar inducida por metotrexato. Semin Fund Esp Reumatol. :176-82.

5. Alarcón GS, Kremer JM, Macaluso M, Weinblatt ME, Cannon GW, Palmer WR, et al. Risk factors for methotrexate-induced lung injury in patients with rheumatoid arthritis. A multicenter, case-control study. Methotrexate-Lung Study Group. Ann
Intern Med. 1 de septiembre de 1997;127(5):356-64.

6. Beyeler C, Jordi B, Gerber NJ, Im Hof V. Pulmonary function in rheumatoid arthritis treated with lowdose methotrexate: a longitudinal study. $\mathrm{Br} J$ Rheumatol. mayo de 1996;35(5):446-52.

7. Mariñosa M, Soler A, Nogués X, Pedro-Botet J. Pulmonary coinfection by Pneumocystis carinii and Aspegillus fumigatus in a seronegative arthritis patient treated with low-dose methotrexate. Clin Rheumatol. diciembre de 2004;23(6):555-6.

8. Roubille C, Haraoui B. Interstitial lung diseases induced or exacerbated by DMARDS and biologic agents in rheumatoid arthritis: A systematic literature review. Semin Arthritis Rheum. abril de 2014;43(5):613-26.

9. Neves C, Jorge R, Barcelos A. [The network of methotrexate toxicity]. Acta Reumatol Port. marzo de 2009;34(1):11-34.

10. Iyyadurai $\mathrm{R}$, Carey $\mathrm{RAB}$, Satyendra S. Low-dose methotrexateinduced acute interstitial pneumonitis: Report of two cases from South India and review of literature. J Fam Med Prim Care. 2016;5(4):875-8. 